\title{
A INVENÇÃO DA TRADUÇÃO: DA IMPORTÂNCIA DA TRADUÇÃO À TRADUÇÃO DESSA IMPORTÂNCIA
}

Mauricio Mendonça Cardozo*

$\mathbf{E}$

ste trabalho, apresentado no âmbito do IV Encontro do Celsul, como parte integrante de uma mesa-redonda de tradução, foi motivado, em grande medida, pela natureza sugestiva do título dessa mesa-redonda: “O Significado da tradução e a tradução do significado". Já de partida, a ausência de aspas aninhando a palavra significado - o que nos redime, num primeiro momento, de um comprometimento terminológico de caráter restritivo - licencia-nos a ler esse título sob uma ótica mais particular.

Gostaríamos de entender a palavra "significado" não segundo uma acepção marcada teoricamente, mas sim, num sentido mais coloquial. Para ilustrar, podemos lembrar de duas das possibilidades de significação da palavra Bedeutung (tradução freqüente para o termo significado) na língua alemã: a primeira, na distinção proposta por Frege na relação entre Sinn e Bedeutung ("sentido e significado" ou, na tradução de Paulo Alcoforado do texto clássico" de Frege, "Sentido e Referência"); a segunda, no uso desse termo em uma frase como "Diese Entscheidung war von grosser Bedeutung für das Land" ("Esta decisão foi de grande importancia para o país"). Pois não é da primeira, e sim

* Universidade Federal do Paraná.

1 FREGE, G. Sobre o Sentido e a Referência, Tradução: Paulo Alcoforado. In: Lógica e filosofia da Linguagem; seleção, introdução, tradução e notas de Paulo Alcoforado. São Paulo, Cultrix, Editora da Universidade de Sāo Paulo, 1978, p. 59-86. 
da segunda possibilidade de significação, mais próxima de uma noção de "significado" como "importância" ou "relevância", que queremos nos aproximar. Desse modo, podemos começar esta exposição "traduzindo" o título da mesa-redonda para: "A importância da tradução e a tradução dessa importância".

Se com isso nos distanciamos de uma conceituação mais lingüística de Significado e, por conseguinte, de uma abordagem mais "lingüística" da tradução, não o fazemos sem um propósito bem claro. Tomamos como pressuposto a idéia de que "tradução" não se resume a uma operação entre pares lingüísticos, como nos faz crer o mito fundador da Torre de Babel. Segundo este, a tradução encontraria o seu Ursprung ${ }^{2}$ no momento em que as pessoas passaram a falar línguas diferentes. Contudo, esse mito representa para a conceituação da tradução a queda do paraíso, pois a noção de uma essência pós-babélica da tradução parece apagar do nosso horizonte de compreensão a possibilidade de que a tradução possa ter outras formas de manifestação. Esse apagamento de uma essência "pré-babélica" ou "supra-babélica" da tradução, isto é, de sua manifestação como fenômeno não essencialmente interlingüístico, não nos parece, senão, apenas um sinal de que é entre um par linguiístico que a tradução se manifesta de modo mais visível.

Essa situação tem uma implicação direta sobre os estudos da tradução. Esse modo de pensar a tradução como sendo um "fenômeno" essencialmente interlingüístico nos é muito presente, tanto como conceito quanto de modo residual no senso comum. Isso nos coíbe de olhar para a tradução com um mínimo de distanciamento que nos possibilite pensá-la em suas manifestações fora do espectro interlingüístico. ${ }^{3}$ Em consequiência disso, esse olhar rotineiro acaba por moldar as concepções de tradução segundo o meio em que ela se manifesta mais visivelmente, não levando em consideração o fato de que a observação de outras formas de manifestação da tradução podem lançar uma luz sobre dilemas que a análise de sua manifestação interlinguiística até hoje não pôde resolver. É como se esse olhar exclusivo para a manifestação interlingüística da tradução construísse, por negação, uma face oculta da essência da tradução, cuja existência raramente é cogitada. Traduzindo: sofremos de um certa cegueira

2 Sua origem, sua manifestação primeva;

3 Não entraremos aqui no mérito dessa questão, mas poderíamos aludir a algumas outras formas de manifestações da tradução fora desse espectro interlingüístico: a verbalizaçāo como tradução do pensamento; a essência tradutória de algumas figuras de linguagem como a metáfora e a paráfrase (mesmo num plano intra-lingüístico); a tradução intersemiótica; as ciências naturais como trađução das macro e micro-estruturas da natureza; a psicanálise, a história e a literatura como tradução da natureza humana; entre outras. Não será por mero acaso que, nas áreas citadas, encontraremos discussões epistemológicas de natureza muito semelhante à que se faz presente nos estudos da tradução. 
epistemológica, de uma impossibilidade de exercício do olhar sobre a natureza da tradução para além do seu desdobramento interlingüístico.

Contudo, não se pode ignorar o mérito desse olhar consuetudinário, pois foi a partir de uma tradição de olhares sobre a tradução, enquanto manifestação interlingüística, que se construiu a sua importância. Mas, se por um lado o olhar pós-babélico foi e é capaz de revelar a "importância da tradução", por outro lado, esse olhar parece ser incapaz de "traduzir essa importância". É preciso, portanto, projetar sobre a tradução um olhar distanciado, estrangeiro, que perceba, naquilo que nos parece tão comum, a diferença. Acreditamos que desviando o foco de atenção dos aspectos estritamente interlingüísticos da tradução, poderemos descobrir algo de novo no âmbito dessa reflexão, que não represente uma simples repetição dos passos dados nos últimos 2500 anos de registros de reflexões sobre a tradução na cultura ocidental.

Em outras palavras, o exercício de distanciamento que propomos como prática resume-se, primeiramente, em pensar a tradução em outra situação que não a de mediação entre duas línguas, ou seja, traduzir a própria reflexão sobre tradução em um outro espaço de reflexão e com outras ferramentas, para, num segundo momento, cotejar os ganhos dessa reflexão com a reflexão sobre tradução enquanto manifestação interlinguiística e, por fim, esboçar um retrato mais completo da essência desse fenômeno que supomos não exclusivamente interlingüístico.

Mas esse exercício de distanciamento aqui proposto é muito menos heterodoxo do que nos possa parecer. Ao longo da história dos estudos da tradução, há grande recorrência, por exemplo, do uso da metáfora como instrumento de reflexão. Basta lembrarmos da metáfora clássica das "Belas infiéis", que compara a tradução à figura de uma mulher, que se bela, não há como ser fiel e, se fiel, não há como ser bela. Ou a bela metáfora do poeta alemão Heinrich Heine, segundo a qual traduzir seria como "empalhar raios de sol". Ou ainda as metáforas de Walter Benjamin em seu ensaio "A tarefa do tradutor", 4 em que ele constrói sua concepção de tradução a partir de retas tangentes, cacos de vaso e o mito judaico da língua pura. Ora, tais tentativas de metaforização do fenômeno tradutório parecem representar justamente um esforço de pensar a tradução em outros termos que não os interlingüísticos e são, simultaneamente, uma prova de que tal esforço é, no mínimo, muito ilustrativo.

Como breve ilustração desse exercício de distanciamento, faremos, aqui, o encaminhamento inicial à discussão da noção de autoria na relação escritor-

4 BENJAMIN, W. Die Aufgabe des Übersetzers. In: VERLAG, S. Iluminationen. [S. 1.: s. n.], 1994, p. 50-62. 
tradutor (tema pertinente sobretudo à área dos estudos da Tradução Literária) com base nessa perspectiva. Para tanto, gostaríamos de fazer referência a uma passagem de uma conversa entre os físicos Werner Heisenberg e Carl Friedrich von Weizsäcker, datada do dia 07 de agosto de 1945, um dia após o lançamento da bomba atômica sobre Hiroshima. Nessa conversa, em que os dois físicos discutem a carga de responsabilidade do cientista frente aos acontecimentos desencadeados a partir de sua própria produção científica, Carl Friedrich von Weizsäcker faz uma distinção entre "descobridores" e "inventores":

É provável que devamos estabelecer uma distinção clara entre o descobridor e o inventor. Em geral, o primeiro não pode prever as possibilidades de aplicação de sua contribuição, pois o caminho para sua utilização prática pode estar tão distante que as previsões tornam-se impossíveis. Os inventores parecem estar numa situação bem diferente. Eles têm um objetivo prático e definido em vista e têm que ser capazes de julgar seu mérito. Aparentemente, portanto, podemos responsabiliza-los por suas contribuições. No entanto, é justamente o inventor que pode ser visto agindo menos em proveito próprio do que em benefício da sociedade como um todo. [...] Logo, também a ele não se pode atribuir mais do que uma responsabilidade parcial, sobretudo porque nem ele nem a sociedade são capazes de prever todas as conseqüências posteriores de sua invenção. [...] Em suma, tudo o que se pode realmente pedir ao indivíduo é que ele preste uma atenção criteriosa e escrupulosa ao contexto mais amplo em que deve enquadrar-se todo o progresso científico e técnico, mesmo que isso não pareça favorecer seus interesses imediatos. (Heisenberg, 1996, p. 228f - grifo nosso)

Não vamos desenvolver, aqui, a questão ética central a essa conversa e muito atual nestes nossos tempos, sobretudo em vista dos grandes avanços na área da pesquisa genética. Mas podemos aproveitar a distinção que aí se faz entre "descobridores" e "inventores".

É particularmente interessante notar que tanto na noção de descoberta quanto na noção de invenção, o físico alemão dissolve a noção de responsabilidade atribuída ao sujeito "descobridor" e "inventor": daquele, por não poder antecipar a importância de suas descobertas; deste, por ser pautado por aquilo que a coletividade e o seu tempo entende como sendo importante naquele momento. 
Podemos citar alguns exemplos como a descoberta da técnica de fissão do urânio, pelo cientista Otto Hahn, e a invenção da bomba atômica; ou, um caso menos drástico, a relação das descobertas de Galvani e Volta, na área da eletrotécnica, e os progressos do mundo eletro-eletrônico atual. E certamente poderíamos ir além, citando cadeias de descobridores e inventores como Descartes, Galileu, Kepler e Newton.

O que parece estar em jogo aí, associada à idéia de dissolução da responsabilidade, é uma noção reelaborada da importância da autoria, seja do sujeito descobridor ou do sujeito inventor. Isso porque, na física, parece reconhecer-se em cada nova descoberta uma invenção a partir de uma descoberta anterior e assim por diante. É nesse sentido que Newton, na historiografia científica, é apresentado como um grande descobridor, mas, ao mesmo tempo, segundo alguns historiadores, Descartes é que teria tornado Newton possível.

Assim, se por um instante, descoberta e invenção parecem ser apresentadas como coisas distintas, ainda que pela anterioridade cronológica da primeira em relação à segunda, não há, no entanto, nenhuma relação hierárquica entre ambas, no sentido de ressaltar a maior importância de uma em relação à outra. Ao contrário, uma é apresentada como a possibilidade de existência da outra: a descoberta é subsídio para uma invenção que, por sua vez, torna-se instrumento para a realização de uma nova descoberta, e assim por diante. Trata-se, portanto, de uma noção contínua de transformação do conhecimento, que, no entanto, só é possível a partir do desenvolvimento de uma capacidade do sujeito inventor de, por um lado, perceber a importância de uma descoberta e, por outro lado, traduzir essa descoberta em uma nova invenção.

Agora, redirecionando o olhar para a tradução, mas mantendo ainda na retina a imagem acima, lembremos de uma entrevista concedida a Günter Lorenz pelo escritor João Guimarães Rosa, em que este afirma: "O escritor [...] é um descobridor;"(Lorenz, 1994). Ora, essa afirmação nos serve de "deixa" para sugerir os termos restantes dessa comparação: "o escritor é um descobridor" e o tradutor, um inventor.

Se na física tudo aponta para uma dissolução da distinção entre descobridores e inventores, ou, em outras palavras, para uma reelaboração dessa relação como duas faces de uma mesma moeda, quando tratamos de escritores e tradutores - em sua relação interlingüística mediada pela tradução -, esse processo de reelaboração parece ser ainda muito incipiente. Por um lado, a afirmação de Guimarães Rosa não parece causar espécie, pois não é algo fora do comum pensar os escritores como criadores ou descobridores: do mundo particular de suas obras ou até mesmo de seus precursores, como afirma Jorge Luis 
Borges. Mas, por outro lado, no que se refere aos tradutores, parece haver grande resistência em aceitar a sua produção como invenção.

Podemos localizar o problema em dois pontos centrais: o primeiro diz respeito à forte presença de uma concepção de tradução construída a partir de uma visão mitificada da linguagem, que pressupõe coisas como a possibilidade de estabelecer-se uma equivalência total entre as línguas e a possibilidade de alcançar-se a neutralidade absoluta no exercício da tradução, a crença na figura do autor como ser soberano de suas intenções e plenamente consciente de seus atos, a crença na idealidade da escritura como um meio de comunicação e na idealidade da própria comunicação; o segundo ponto refere-se à falta de elaboração do conceito de autoria a partir de uma perspectiva não exclusivamente interlingüística. A perpetuação de uma imagem proverbial do tradutor como um traidor e como um elemento idealmente neutro na cadeia de transformação do conhecimento - em contraste à imagem do autor criador, marcada fortemente pelo ideário romântico - não contribui em nada para uma rediscussão, sobre uma ótica diferente, da concepção de tradução presente de modo residual no senso-comum.

Como vimos, também na física é forte a presença de uma noção de autoria - entre descobridores, inventores e suas produções. Aliás, no campo da física a autoria é por vezes associada, até mesmo, a uma noção de paternidade (o Pai da física moderna, o Pai da física quântica etc.). Se a discussão do conceito de autoria é uma questão comum tanto à física como aos estudos da tradução, sobretudo à tradução literária, e se, à diferença do que ocorre nesta, naquela área observamos uma evolução nesse campo de discussão, então podemos levantar a seguinte pergunta: não seria possível aproveitar os ganhos epistemológicos da física em proveito das questões de tradução ?

É importante salientar que o encaminhamento que aqui se faz a essa discussão não objetiva exclusivamente apagar a imagem do autor como criador, passando o crédito de criação exclusivamente ao tradutor. Ao contrário, uma reflexão como esta visa apenas contribuir para a dissolução da crença no caráter etéreo da criação - como se os autores escrevessem suas obras a partir do nada, como se as suas próprias obras não pudessem ser entendidas como uma espécie de tradução - e para a desmitificação da crença na neutralidade e do tradutor, como se lhe fosse possível traduzir sem inscrever na escritura as suas marcas, ignorando o fato de que também ele está sujeito aos corolários do princípio da incerteza de Heisenberg ${ }^{5}$ levado às últimas consequiências. $\mathrm{O}$ objetivo desse

5 Segundo o Princípio da Incerteza de Heisenberg (Werner Heisenberg), desenvolvido no âmbito da física quântica, o próprio ato de observação já implica em uma modificação do fenômeno observado. 
olhar diferenciado é sugerir uma perspectiva de análise da relação autor-tradutor análoga à dimensão da relação descobridor-inventor, em que os sujeitos envolvidos são apenas elementos operadores desse processo contínuo de transformação do conhecimento.

Não é possível, no âmbito deste trabalho, discutir todas as implicações pertinentes ao redimensionamento dessa relação autor-tradutor. No entanto, uma vez encaminhada a discussão a partir da perspectiva aqui definida, não é improvável sustentar que esse redimensionamento, exemplificado aqui a partir do paralelo traçado com a física, seja capaz de fomentar uma rediscussão dos pressupostos que sustentam a concepção de tradução presente em nossas avaliações mais cotidianas, provocando assim um movimento produtivo de distanciamento e possibilitando o exercício de um olhar diferençado sobre a natureza do fenômeno tradutório.

Por fim, voltemos ao subtítulo deste trabalho: da importância da tradução à tradução dessa importância. A “importância da tradução" parece ser algo estabelecido. Ninguém há de desprezar o papel central da tradução na formação de línguas, literaturas, nações, religiões, ciências. Mas não é por acaso que essa importância da tradução esteja intimamente relacionada à sua manifestação interlingüística.

Já a "tradução dessa importância" requer um outro olhar sobre o fenômeno da tradução, um olhar que a apreenda em toda a amplitude de sua natureza suprababélica. Mas ainda somos cegos. É preciso inventar um outro olhar. Para descobrir a importância da tradução, recorremos à sua essência pós-babélica, nós a descobrimos em sua manifestação interlingüística. Mas para traduzir essa importância, é preciso enxergar a tradução além desse modo de manifestação. Para enxergá-la como invenção, é preciso ainda inventá-la como invenção.

\section{RESUMO}

O presente artigo levanta a hipótese de que o modo de entender a tradução como fenômeno exclusivamente interlingüístico limita a compreensão da natureza desta, e sugere um encaminhamento para essa discussão no sentido de demonstrar como é possível lançar uma luz sobre as questões de tradução com base no ganho epistemológico de outras áreas do conhecimento.

Palavras-Chave: Tradução, invenção, autoria, fisica moderna. 


\section{ZUSAMMENFASSUNG}

In diesem Aufsatz wird behauptet, dass eine Behandlung der Übersetzung, die davon ausgeht, dass die Übersetzung exclusiv als zwischensprachliches Phänomen zu verstehen sei, nicht ausreicht, um sie in der Ganzheit ihrer Natur zu begreifen. Es wird dann gezeigt, wie neue Erkenntnisse zu den Fragestellungen der Übersetzungswissenschaft gewonnen werden können, indem man versucht, das Übersetzungphänomen mit Hilfe des epistemologischen Gewinns anderer Wissenschaften zu verstehen.

Schlüsselwörter: Übersetzung, evfindung, autorschaft, quantenmechanik.

\section{REFERÊNCIAS}

HEISENBERG, W. Sobre a responsabilidade do pesquisador. In: HEISENBERG, W. $A$ parte $e$ o todo: encontros e conversas sobre física, filosofia, religião e política. Tradução: Vera Ribeiro. Rio de Janeiro: Contraponto, 1996. p. 225-238.

LORENZ, G. Diálogo com Guimarães Rosa. In: ROSA, J. G. Ficção completa. Rio de Janeiro: Nova Aguilar, 1994. v. 1, p. 40. 